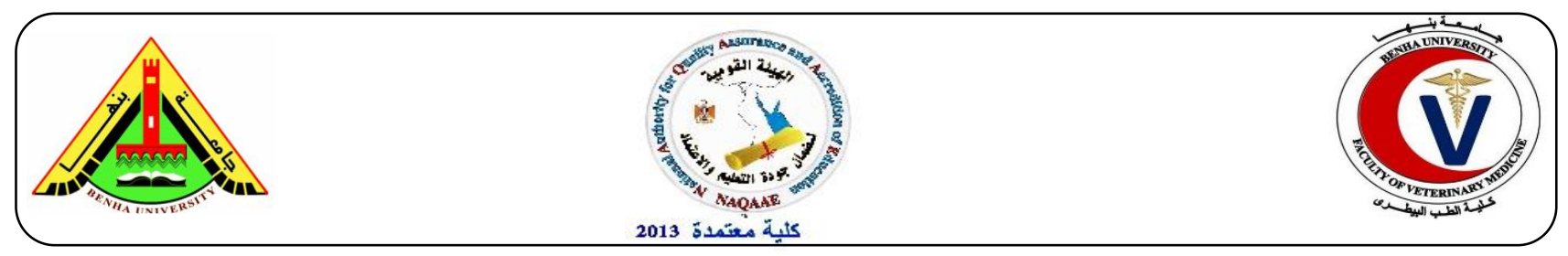

\title{
Efficacy of different cow side tests for diagnosis of ketosis in lactating cows
}

\author{
Ghanem, M.M. ${ }^{1 *}$, Mahmoud, M.E. ${ }^{2}$, Abd El-Raof, Y.M. ${ }^{1}$, El-Attar, H.M. ${ }^{1}$ \\ ${ }^{1}$ Animal Medicine Department, Faculty of Vet. Medicine, Benha University, \\ ${ }^{2}$ Animal Medicine Dept., Faculty of Veterinary Medicine, Aswan University. \\ Corresponding author: mohamed.ghanem@fvtm.bu.edu.eg
}

\section{A B S T R A C T}

The aim of this work was to compare the efficacy of different cow side tests for diagnosis of ketosis including Precision Xtra ketone method and PortaBHB milk ketone tests in Holstein- Friesian dairy cows. The colorimetric estimation of serum BHBA at a cut-off point $\geq 1.200 \mathrm{mmol} / \mathrm{L}$ was used as a gold standard method. For that purpose, 200 Holstein- Friesian dairy cows up to 6 weeks postpartum were tested. The prevalence of ketosis was $11 \%$ by using colorimetric method. The apparent prevalence of ketosis was $12.5 \%$ by using of Precision Xtra ketone test at a cut-off point of blood BHBA $\geq 1.200 \mathrm{mmol} / \mathrm{L}$ with $90.9 \%$ sensitivity, $97.2 \%$ specificity, $80 \%$ positive predictive value (PPV) and $98.9 \%$ negative predictive value (NPV). A significant correlation $(\mathrm{r}=0.871 ; P<0.01)$ was recorded between serum BHBA measured by colorimetric method and whole blood BHBA measured by Precision Xtra ketone test. The apparent prevalence of ketosis was $20.5 \%$ and $6.5 \%$ by using PortaBHB milk ketone test at a cut- off point 100-200 $\mu \mathrm{mol}$ of milk BHBA /L with $86.4 \%$ and $45.5 \%$ sensitivity, $87.6 \%$ and $98.3 \%$ specificity, $46.3 \%$ and $76.9 \%$ PPV and $98.1 \%$ and $93.6 \%$ NPV, respectively. It was concluded that Precision Xtra ketone test and PortaBHB milk ketone test are simple and rapid tools for diagnosis of ketosis compared with the standard colorimetric method. However, Precision Xtra ketone test is more accurate and sensitive than PortaBHB milk ketone test.

Keywords: cow side tests, Ketosis, PortaBHB milk ketone test, Precision Xtra ketone test

(http://www.bvmj.bu.edu.eg) (BVMJ-31(2): 225-230, 2016)

\section{INTRODUCTION}

Ketosis is a major metabolic disorder of dairy cows in early lactation, which develops when dairy cows fall into a condition of excessively negative energy balance (NEB) caused by insufficient dietary intake and generous lactation (Xu et al.,2010). Ketosis characterized by relatively high concentrations of the ketone bodies acetoacetate, $\beta$ hydroxybutyrate (BHBA) and acetone, and a concurrent low concentration of glucose in the blood (Melendez et al.,2006). The gold standard test for diagnosis of ketosis is measurement of ketone bodies in serum or plasma photometrically in a diagnostic laboratory. BHBA is used most frequently due to its stability in samples (Herdt, 2000). Concentration of $\mathrm{BHB}>1.200 \mathrm{mmol} / \mathrm{L}$ is used as the defining threshold of subclinical ketosis (Oetzel, 2012). There are two cow-side tests that are currently accepted a sufficiently accurate for routine use: PortaBHB milk test strips (PortaCheck Inc., Moorestown, NJ) for measurement of milk BHBA and Precision Xtra ketone meter test (Abbott Laboratories, Abbott Park, IL) for measurement of blood BHB (Iwersen et al.,2009 and Denis-Robichaud et al., 2011). The prevalence of ketosis in Egypt is not well defined although the disease causes great economic losses.

Aim: comparison the efficacy of different cow side tests for diagnosis of ketosis including Precision Xtra ketone method and PortaBHB milk ketone tests in Holstein- Friesian dairy cows

\section{MATERIAL AND METHODS}

\subsection{Animals and design:}

This study was implemented on 200 lactating Holstein- Friesian cows of different ages (3- 10 years old) during post parturient period up to 6 weeks postpartum with average of daily milk production $(28.47 \pm 2.96) \mathrm{kg} /$ day varies from $13-50 \mathrm{~kg} / \mathrm{day}$, These cows were located in eight dairy farms in four governorates (Kalubia, Dakhalia, Menofia and Ismailia governorates). According to colorimetric enzymatic method diagnosis of ketosis at a cut-off point $1.200 \mathrm{mmol} / \mathrm{L}$ (Duffield, 2000 and Zhang et al., 2012a) these cows were classified into 2 groups. Group 1 included control cows ( $\mathrm{n}=178$ cows) 
negative with colorimetric enzymatic method. Group 2 included (22 cows) which are positive with colorimetric enzymatic method.

All 200 cows enrolled in this study were tested by Precision Xtra ketone test for detection of ketosis in blood at a cut - off point of blood BHBA $\geq 1.200$ $\mathrm{mmol} / \mathrm{L}$ and PortaBHB milk ketone test at a cut- off point 100 and $200 \mu \mathrm{mol}$ of $\mathrm{BHBA} / \mathrm{L}$ to detect positive and negative cases for ketosis.

\subsection{Samples.}

\subsubsection{Blood and serum Samples.}

The blood sample was collected from jugular vein of all cows during postpartum period during the early morning (Kelly, 1984). Two types of blood samples were collected including whole blood for detection of blood BHBA by Precision Xtra ketone test and serum samples for detection of serum BHBA by colorimetric enzymatic method analysis.

\subsubsection{Milk samples.}

Left fore quarter strip samples were collected after udder preparation (Denis-Robichaud et al., 2011).

\subsection{Diagnosis of ketosis by enzymatic laboratory test}

Williamson et al. (1962) developed an enzyme catalysis method to test serum BHBA. Based on this method, a test kit was manufactured. The test kit required the use of an ultraviolet spectrophotometer or biochemistry analyzer and could be used to test the serum BHBA levels of humans and animals. Beta- hydroxybutyrate (BHBA) (Randox Laboratories Ltd, UK,)

\section{4. cow side tests}

\subsubsection{Precision Xtra ketone test.}

The Precision Xtra meter is a hand-held device that measures BHBA in fresh whole blood samples. Precision Xtra ketone strip contains the enzyme $\beta$-hydroxybutyrate dehydrogenase, which oxidizes BHBA to acetoacetate. This reduces nicotinamide adenine dinucleotide (NAD+) to $\mathrm{NADH}$. NADH is then reoxidized to NAD+ by an electron transfer mediator molecule. The electrical current generated by this conversion is measured by the electronic hand-held BHBA meter and is directly proportional to BHBA concentration.

\subsubsection{PortaBHB milk ketone test.}

The PortaBHB milk ketone test is a semiquantitative dipstick for the detection of subclinical ketosis (PortaCheck, Inc, Moorestown, NJ). It is used for detection of BHBA in milk it contains color chart provided on the test bottle $(0,50,100$, 200 , or $500 \mu \mathrm{mol} / \mathrm{L}$ ).

\subsection{Statistical analysis.}

Correlation coefficient (r) between serum BHBA measured by the colorimetric enzymatic laboratory method and blood BHBA values displayed on Precision Xtra ketone test was calculated by using Spearman's rank correlation analysis by using of the Sigma Stat 3.1, statistical software.

Prevalence of a disease is calculated by Beaglehole et al. (1993) by the following equation: Prevalence=

$$
\begin{aligned}
& \frac{\text { Number ofcows with disease or condition at specified time }}{\text { Number ofcows in the population at risk at specified time }}(\mathrm{x} 100) . \\
& \text { True prevalence }=\frac{\text { Apparent prevalence }+S p-1}{S e+S P-1}(\mathrm{x} 100)(\text { Carrier et al., 2004) }
\end{aligned}
$$

For evaluation of cow side tests for field detection of ketosis according to method described by (Lalkhen and McCluskey, 2008) the following terms and equations were used: Sensitivity of Precision Xtra ketone test and PortaBHB test was calculated by following equation:

$$
\begin{gathered}
\text { Sensitivity }=\frac{\text { True positive }}{\text { True positive+False negative }}(\text { x 100) } \\
\text { Specificity }=\frac{\text { True negative }}{\text { True negative+False positive }}(\text { x 100) } \\
\text { PPV }=\frac{\text { True positive }}{\text { True positive+False positive }}(\text { x 100) } \\
\text { NPV }=\frac{\text { True negative }}{\text { True negative+False negative }}(\text { x 100) }
\end{gathered}
$$

\section{RESULTS}
3.1. Prevalence of ketosis by the gold standard colorimetric method

As shown in Table 1 , the true prevalence of ketosis was $11 \%$ by using colorimetric enzymatic method which is the gold standard method for diagnosis of ketosis (Duffield, 2000 and Oetzel, 2007) as 22 cows suffered from ketosis from 200 
Holstein - Friesian dairy cows enrolled in this survey at a cut-off point of serum $\mathrm{BHBA} \geq 1.200 \mathrm{mmol} / \mathrm{L}$.

\subsection{Prevalence of ketosis by different cow side tests}

The apparent prevalence of ketosis was $12.5 \%$ by using of Precision Xtra ketone test at a cut- off point of blood BHBA $\geq 1,200 \mathrm{mmol} / \mathrm{L}$. Some values of BHBA measured by Precision Xtra ketone test were illustrated in Figure $1(a-b)$. The apparent prevalence of ketosis was $20.5 \%$ by using PortaBHB milk ketone test at a cut- off point $100 \mu \mathrm{mol}$ of BHBA $/ \mathrm{L}$. The apparent prevalence of ketosis was $6.5 \%$ by using PortaBHB milk ketone test at a cut-off point 200 $\mu$ mol of BHBA/L (Table1). The changes in the color of PortaBHB milk ketone test strips are illustrated in Figure 2

\subsection{Evaluation of sensitivity and specificity of Precision Xtra ketone test and PortaBHB milk ketone test.}

Precision Xtra ketone test had $90.9 \%$ sensitivity, $97.2 \%$ specificity, $80 \%$ positive predictive value and 98.9\% negative predictive value at a cut-off point $\geq 1,200 \mathrm{mmol}$ of blood BHBA /L (Table 2).

The correlation between BHBA in serum measured by (colorimetric enzymatic method laboratory method - BHB mmol/L) and BHBA of whole blood measured by (Precision Xtra test - BHB $\mathrm{mmol} / \mathrm{L}$ ) showed a significant positive correlation coefficient $\mathrm{r}=0.871 ; \quad p<0.01 ;$ no of cows $=200$ (Figure 3).

PortaBHB milk strips had $86.4 \%$ sensitivity, 87.6 $\%$ specificity, $46.3 \%$ positive predictive value and $98.1 \%$ negative predictive value at a cut- off point $100 \mu \mathrm{mol}$ of BHBA /L. (Table 2). PortaBHB milk ketone test had $45.5 \%$ sensitivity, $98.3 \%$ specificity, $76.9 \%$ positive predictive value and $93.6 \%$ negative predictive value at a cut-off $200 \mu \mathrm{mol}$ of BHBA /L (Table 2)

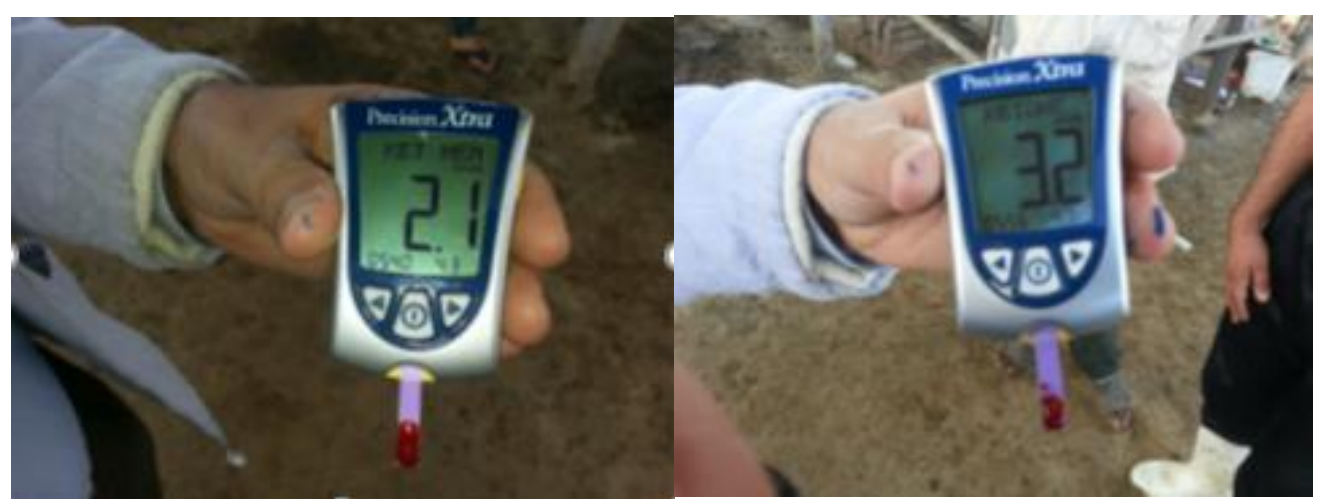

Figure (1a)

Figure(1b)

Figure 1 (a-b) Demonstration of some values of blood BHBA measured by Precision Xtra ketone test using blood samples.

Table 1 The prevalence of ketosis by different diagnostic methods

\begin{tabular}{|c|c|c|c|c|}
\hline \multirow[b]{2}{*}{ Parameters } & \multirow{2}{*}{$\begin{array}{l}\text { Serum BHBA by } \\
\text { Colorimetric enzymatic } \\
\text { method at a cut }- \text { off } \\
\geq 1.200 \mathrm{mmol} / \mathrm{L}\end{array}$} & \multirow{2}{*}{$\begin{array}{c}\text { Blood BHBA by Precision } \\
\text { Xtra ketone test } \\
\text { at a cut- off } \\
\geq 12.00 / \mathrm{mmol} / \mathrm{L}\end{array}$} & \multicolumn{2}{|c|}{$\begin{array}{l}\text { Milk BHBA by } \\
\text { PortaBHB milk ketone test }\end{array}$} \\
\hline & & & $\begin{array}{l}\text { at a cut }- \\
\text { off } \geq 100 \\
\mu \mathrm{mol} / \mathrm{L}\end{array}$ & $\begin{array}{l}\text { at a cut }- \\
\text { off } \geq 200 \\
\mu \mathrm{mol} / \mathrm{L}\end{array}$ \\
\hline No. of examined cows & 200 & 200 & 200 & 200 \\
\hline $\begin{array}{l}\text { No. of cows } \\
\text { Tested positive }\end{array}$ & 22 & 25 & 41 & 13 \\
\hline $\begin{array}{l}\text { True or Apparent } \\
\text { prevalence\% }\end{array}$ & $11 \%$ & $12.5 \%$ & $20.5 \%$ & $6.5 \%$ \\
\hline
\end{tabular}




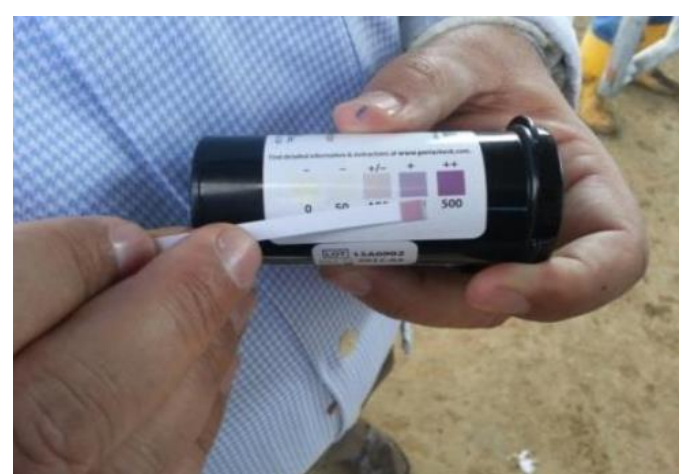

Figure 2 the change in the color of PortaBHB milk ketone test strips on milk samples.

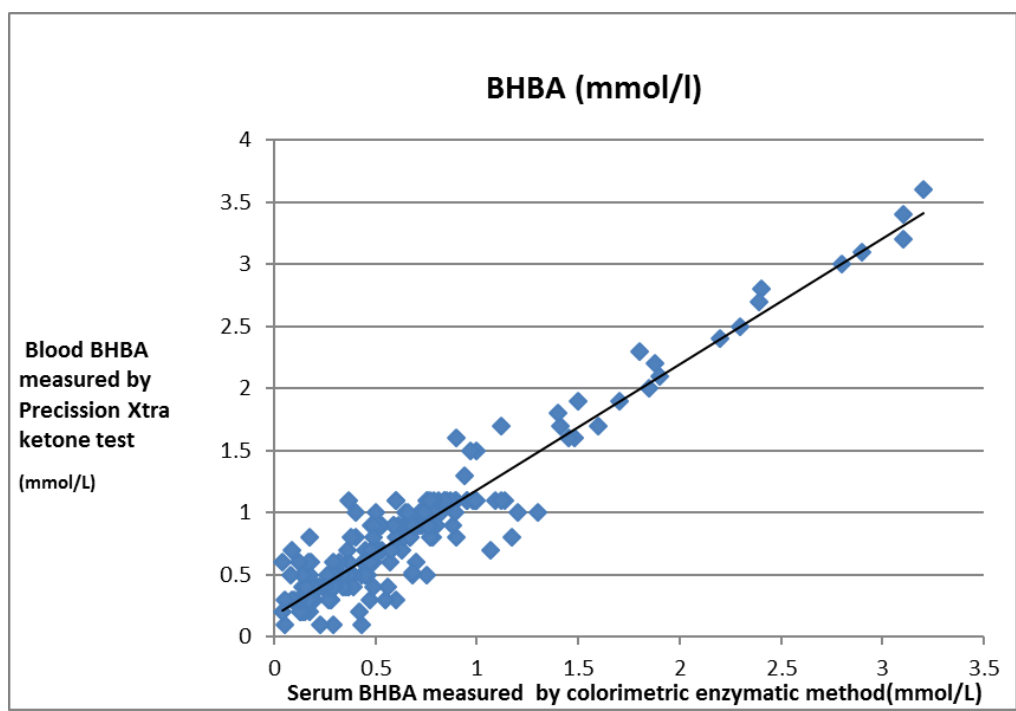

Figure 3 Correlation between BHBA in serum measured by (colorimetric enzymatic method $\mathrm{mmol} / \mathrm{L}$ ) and BHBA of whole blood measured by (Precision Xtra ketone test $-\mathrm{mmol} / \mathrm{L}$ ).

Table 2 Sensitivity, specificity, PPV and NPV of Precision Xtra ketone test at a cut-off point of blood BHBA $\geq 1.200 \mathrm{mmol} / / \mathrm{L}$ and PortaBHB milk ketone test at a cut- off point 100-200 $\mu \mathrm{mol}$ of BHBA /L.

\begin{tabular}{lccc}
\hline & $\begin{array}{c}\text { Blood BHBA by } \\
\text { Precision Xtra ketone test } \\
\text { at a cut - off point } \geq \\
1.200 \text { mmol/L }\end{array}$ & $\begin{array}{c}\text { Milk BHBA by } \\
\text { PortaBHB milk ketone test at a cut }- \text { off } \\
\geq 100 \mu \mathrm{mol} \text { of } \\
\text { BHBA/L }\end{array}$ & $\begin{array}{l}\geq 200 \mu \mathrm{mol} \text { of BHBA } \\
/ \mathrm{L}\end{array}$ \\
\hline Parameters & 200 & 200 & 200 \\
Total examined cows & 20 & 19 & 10 \\
True positive & 5 & 22 & 3 \\
False positive & 173 & 156 & 175 \\
True negative & 2 & 3 & 12 \\
False negative & $90.9 \%$ & $86.4 \%$ & $45.5 \%$ \\
Sensitivity & $80 \%$ & $46.3 \%$ & $76.9 \%$ \\
PPV & $97.2 \%$ & $87.6 \%$ & $98.3 \%$ \\
Specificity & $98.9 \%$ & $98.1 \%$ & $93.6 \%$ \\
NPV & & & \\
\hline
\end{tabular}




\section{DISCUSSION}

The precision Xtra ketone test had 90.9\% sensitivity, $97.2 \%$ specificity, $80 \%$ positive predictive value and $98.9 \%$ negative predictive value at a cut-off point of blood BHBA $\geq 1.200$ $\mathrm{mmol} / \mathrm{L}$. This result is in lined with that recorded (Oetzel and McGuirk, 2009) who recorded 91\% sensitivity and $94 \%$ specificity of Precision Xtra ketone test for the diagnosis of ketosis. Moreover, Iwersen et al. (2009) reported that Precision Xtra ketone test had $88 \%$ sensitivity and $96 \%$ specificity, $82 \%$ positive predictive value and $98 \%$ negative predictive value at a cut- off point 1.200 mmol of BHBA /L of whole blood.

Correlation between serum BHBA measured by laboratory colorimetric method - BHB $\mathrm{mmol} / \mathrm{L}$ and blood BHBA measured by Precision Xtra test - BHB $\mathrm{mmol} / \mathrm{L}$ showed a significant positive correlation ( $\mathrm{r}$ ) $=0.871 ; \quad P<0.01 ;$ no of cows $=200$. This result complied with those previously recorded (Krempaský et al., 2014) who recorded that $r=0.95$; $P<0.001$ between measurements of whole blood BHBA of dairy cows measured by the Precision Xtra ketone test and serum BHBA concentration measured by photometric method. Additionally, Oetzel, (2013) recorded that correlation coefficient (r) between handheld meter results and laboratory BHBA results were 0.92. These results validating the use of Precision Xtra ketone test for diagnosis of ketosis in cattle. In addition, several advantages have been proposed of using the Precision Xtra ketone test, it is a rapid method i.e. the results are known immediately, accurate method (had a high sensitivity and specificity), the cost of the Precision Xtra ketone test is less than the cost of laboratory testing, only a small blood sample is required and simple method as there is no need to process or mail serum or plasma samples to a laboratory.

The PortaBHB milk ketone test had $86.4 \%$ sensitivity, $87.6 \%$ specificity, $46.3 \%$ positive predictive value and $98.1 \%$ negative predictive value at a cut- off point $100 \mu \mathrm{mol}$ of BHBA/L. This result is lined with those of Denis-Robichaud et al. (2011) who reported that PortaBHB milk ketone test had $92 \%$ sensitivity, $78.1 \%$ specificity, $58.5 \%$ positive predictive value and $97.7 \%$ negative predictive value at a cut- off point $100 \mu \mathrm{mol}$ of BHBA /L.

On the other hand, the PortaBHB milk ketone test had $45.5 \%$ sensitivity, $98.3 \%$ specificity, $76.9 \%$ positive predictive value and $93.6 \%$ negative predictive value at a cut-off point 200 $\mu \mathrm{mol}$ of BHBA $/ \mathrm{L}$. This result is comparable to those observed by Denis-Robichaud et al. (2011). Who reported that PortaBHB milk ketone test had $50.7 \%$ sensitivity and $99.7 \%$ specificity, $92.7 \%$ positive predictive value and $85.7 \%$ negative predictive value at a cut- off point $200 \mu \mathrm{mol} / \mathrm{L}$.

There are several advantages of using PortaBHB milk strips, it is rapid and simple method (ease of collection of milk sample), need minimal training and cheap method. Therefore, farm application of PortaBHB milk ketone test is considered a useful tool to identify cows suffered from ketosis.

\section{CONCLUSION}

Ketosis is a common problem in early lactating Holstein Friesian dairy farms in Egypt. Precision Xtra ketone test is almost simple, accurate and rapid tool compared with diagnostic laboratory colorimetric method for diagnosis of ketosis. PortaBHB milk ketone test can be used for detection of ketosis, but their lower sensitivity and specificity as compared with Precision Xtra ketone test made it less accurate cow side test.

\section{REFERENCES}

Beaglehole, R..Bonita, R. , Kjellstrom, T., (Eds) 1993. Basic Epidemiology. Geneva, World Health Organization.

Carrier, J., Stewart, S., Godden, S., Fetrow, J., Rapnicki, P., 2004.Evaluation and Use of Three Cow Side Tests for Detection of Subclinical Ketosis in Early Postpartum Cows. J. Dairy Sci. 87, 3725-3735.

Denis-Robichaud, J., DesCôteaux, L., Dubuc, J., 2011.Accuracy of a New Milk Strip CowSide Test for Diagnosis of Hyperketonemia. The Bovine Practitioner 45, 297-100.

Duffield, T., 2000. Subclinical ketosis in lactating dairy cattle. Vet. Clin. North Am. Food Anim. Pract.16, 231-253

Herdt, T. H., 2000. Ruminant adaptation to negative energy balance. Influences on the etiology of ketosis and fatty liver. Vet. Clin. North Am. Food Anim. Pract. 16, 215-230.

Iwersen, M., Falkenberg, U., Voigtsberger, R., Forderung, D., Heuwieser, W., 2009. Evaluation of an electronic cowside test to detect subclinical ketosis in dairy cows. J. Dairy Sci.92, 2618- 2624.

Krempaský, M., Maskal'ová, I., Bujňák, L., Vajda, V., 2014. Ketone bodies in blood of dairy cows: Prevalence and monitoring of subclinical ketosis. Acta Vet. Brno 83, 411416.

Lalkhen, A.G., McCluskey, A., 2008. Clinical tests: sensitivity and specificity. Continuing 
education. in anesthesia. Crit. Care Pain 8, 221-223.

Melendez, P., Goff, J. P., Risco, C. A., Archbald, L. F., Littell, R., Donovan, G. A., 2006. Incidence of subclinical ketosis in cows supplemented with a monensin controlledrelease capsule in Holstein cattle, Florida, USA. Preventive Veterinary Medicine73, 33-42.

Oetzel, G.R., 2007. Herd-level ketosis - diagnosis and risk factors. In: Pre-conference Seminar 7C: Dairy Herd Problem Investigation Strategies: Transition Cow Troubleshooting, 40th Annual Conference of the American Association of Bovine Practitioners, Vancouver, BC, Canada, Pp. 67-91.

Oetzel, G., McGuirk, S., 2009. Fact sheet Cow side Blood BHBA Testing with a Hand-Held "Ketometer University of WisconsinMadison Fact Sheet4, 1-4.
Oetzel, G. R., 2013. Understanding the impact of subclinical ketosis. 24th ruminant nutrition symposium. Available at: http://dairy.ifas. ufl.edu /rns/ 2013/ 2_oetzel.pdf. Last modified February 2013. Accessed February, 2013

Oetzel, G. R., 2012.Understanding the impact of subclinical ketosis. Proc. Of the Cornell Nutrition conference for feed manufacturer.

Williamson, D.H., Mellanby, J., Krebs, H.A., 1962. Enzymatic determination of D (-)- $\beta-$ hydroxybutyric acid and acetoacetic acid in blood. Biochem J. 82, 90-96.

Xu, C., Wang, Z., Liu, G., Li, X.; Xie, G., Xia, C., Zhang, H. Y., 2008. Metabolic characteristic of the liver of dairy cows during ketosis based on comparative proteomics. AsianAust. J. Anim. Sci.21, 1003-1010.

Zhang, Z., Liu, G., Wang, H., Li, X., Wang, Z., 2012a. Detection of subclinical ketosis in dairy cows. Pak Vet J.32, 156-160. 